\title{
IDENTIDADES FEMININAS SILENCIADAS EM ESCOLAS PÚBLICAS DA PERIFERIA DO DISTRITO FEDERAL
}

(Feminine identities silenced in public schools of the periphery of the federal district)

\author{
Flávia Aparecida de Souza Luiz ${ }^{1}$ \\ Universidade de Brasília
}

Maria Luiza M. S. Coroa ${ }^{2}$

Universidade de Brasília

\begin{abstract}
RESUMO
É sob o referencial teórico-metodológico da Análise de Discurso Crítica, embasada principalmente em Fairclough 2001, Pedro, 1998 e Van Dijk, 2008, que se apoia este estudo para analisar marcas de um discurso hegemônico que visa atribuir identidades de subalternidade feminina com práticas de silenciamento. Os fragmentos compõem um corpus maior de dados gerados em uma escola de periferia de Ceilândia, Distrito Federal sob uma ótica qualitativa. É possível dizer que também na escola as práticas e os hábitos da comunidade que a cercam são observados, por ser espaço de convivência e de continuidade das relações préestabelecidas fora de seus muros e que a maneira como os estudantes e os demais membros da escola se comportam dentro dela está vinculada diretamente a como vivem lá fora. O que leva alunas a silenciamento e à descrença de que tal prática será diferente um dia.
\end{abstract}

Palavras-chaves: Escola. Silenciamento Feminino. Subjugação. Violência Simbólica.

\begin{abstract}
It is under the theoretical-methodological framework of Critical Discourse Analysis based mainly on Fairclough 2001, Pedro, 1998 e Van Dijk, 2008 that this study is supported to analyze marks of a hegemonic discourse that aims to assign female subordinate identities with silencing practices. The fragments compose a larger body of data generated in a school in the outskirts of Ceilândia, Distrito Federal from a qualitative perspective. It is possible to say that also at school the practices and habits of the surrounding community are observed, for being a space of coexistence and continuity of pre-established relationships outside its walls and that the way students and other school members behave within is directly linked to how they live outside. What leads students to the silencing and disbelief that such a practice will be different one day.
\end{abstract}

Keywords: School. Women's Silencing. Subjugation. Symbolic Violence.

\section{RESUMEN}

Es bajo el marco teórico-metodológico del Análisis Crítico del Discurso, basado principalmente en Fairclough 2001, Pedro, 1998 y Van Dijk, 2008, que este estudio está respaldado para analizar las marcas de un discurso hegemónico que tiene como objetivo atribuir identidades de subordinación femenina con prácticas de silenciar. Los fragmentos constituyen un corpus de datos más grande generado en una escuela en las afueras de Ceilândia, Distrito Federal bajo una perspectiva cualitativa. Es posible decir que también en la escuela se observan las prácticas y hábitos de la comunidad que lo rodea, ya que es un espacio para la convivencia y la continuidad de las relaciones preestablecidas fuera de sus paredes y que la forma en que los

\footnotetext{
${ }^{1}$ Flávia Aparecida de Souza Luiz é Mestranda em Linguística pela Universidade de Brasília e professora da Secretaria de Estado de Educação do Distrito Federal.

${ }^{2}$ Maria Luiza M. S. Coroa é Doutora em Linguística pela UNICAMP. Professora da Universidade de Brasília desde 1994, onde atua nas áreas de Semântica e Análise do Discurso. Trabalha com formação inicial e continuada de professores e é autora e organizadora de materiais pedagógicos em vários programas e projetos de formação continuada, entre eles o Programa GESTAR II e o projeto de Alfabetização e Linguagem, da UnB, ligado à Rede Nacional de Formação Continuada de Professores, ambos do MEC.
} 
estudiantes y otros miembros de la escuela comportarse dentro está directamente relacionado con la forma en que viven afuera. Lo que lleva a las alumnas al silencio y a la incredulidad de que tal práctica algún día será diferente.

Palabras clave: Escuela. Silenciamiento Femenino. Subyugación. Violencia Simbólica.

Recebido em: julho 2020

Aceito em: julho 2020

DOI: $10.26512 /$ les.v21i1.32468

\section{INTRODUÇÃO}

"Porque vai continuar a mesma coisa. Não vai mudar nada, professora".

Costumeiramente, as mulheres são alvo de comentários aparentemente inofensivos, que foram, culturalmente, naturalizados. Nem sempre é um ataque frontal e pontual, o que seria de mais fácil identificação; é mais frequentemente um ataque que se insinua, que vem e vai, e assim se faz mais leve no meio das inúmeras palavras e brincadeiras de todo dia. Por serem sutis, tais expressões e atitudes podem passar despercebidas, não são associadas a ideologias, discriminação ou preconceito, ao longo dos anos. Por isso têm vida tão longa. Instalam-se culturalmente e são utilizadas com frequência em casa, na rua, no local de trabalho, nas igrejas, nos bares, nas famílias. Chega a não haver lugar adequado ou escolhido para que elas circulem com maior ou menor frequência, visto que podemos ouvi-las tanto em ambientes simples, quanto nos sofisticados, entre homens ou mulheres. Esse comportamento pode ser sintetizado em um relato de uma das autoras deste estudo:

Desde muito pequena já me incomodavam algumas frases ditas, quer por pessoas próximas ou não, como: "só podia ser mulher"; "duas coisas que gosto: cerveja gelada e mulher quente"; "isto não é coisa para mulher"; "o homem pensa, a mulher dá o que pensar", entre outras e que tinham forte recado às mulheres. Tais dizeres sempre deixavam a ideia de quão pesada, árdua, sofrida e sem nenhum direito deveria ser a vida para quem nasceu mulher. Ouvi-as, por vezes, e nunca pararam de me incomodar. Como cresci e estudei na periferia de Brasília, acreditava que tais expressões, que não só depreciavam as mulheres, mas que as faziam carregar uma bagagem imensa nas costas, eram mais comuns entre pessoas economicamente menos favorecidas. No Ensino Médio, passei a estudar numa escola pública no centro de Brasília e mesmo tendo, aparentemente, mudado de lugar, lá estavam elas. Tempo depois, como professora, ao trabalhar numa grande escola de elite, ouvi as mesmas frases sendo ditas pelos pais, familiares e pelas próprias crianças. Pronto, a barreira econômica tinha sido rompida, o dano era mais sério e profundo do que eu acreditava que poderia ser. $\mathrm{O}$ meu desconforto foi enorme ao perceber que era algo que ia mais fundo e que não perpassava somente pelas classes menos abastadas, mas descobri ser um senso, culturalmente, cristalizado. Anos mais tarde, como professora da Secretaria de Educação do DF, pude notar o quanto as mesmas frases continuavam sendo reproduzidas sem nenhuma modificação.

Era preciso fazer algo concreto e chamar a atenção para o que estava ali, todo dia, e que nem mesmo as adolescentes se davam conta. Por mais que elas, como mulheres recebessem diretamente o peso e a responsabilidade do cuidado e fossem tratadas de forma grosseira ou inferior pelos meninos, elas não tinham visão crítica, tampouco discernimento para "ler" o que estava sendo dito. Essas e outras experiências me fizeram buscar mais sobre 
o que me incomodava há muito tempo, mas que teoricamente eu sabia pouco. Ler Fairclough (2001), Van Dijk (2008), Bourdieu (1989 e 2002), Zanello (2018), entre outros, só reafirmou o desejo de querer aprofundar o assunto nesta pesquisa, por isso sugiro que a Análise do Discurso Crítica irá direcionar e embasar o objeto de estudo escolhido.

Dessa reflexão surgiu a preocupação com uma pesquisa em que se pudesse responder às seguintes questões: os discursos de subjugação chegam ou não às escolas? E se chegam, como chegam: há ou não um silenciamento da mulher? Se há, quão agressivo pode ser ele?

Para responder a esses questionamentos, uma pesquisa mais ampla, ainda em andamento, aborda dados gerados em duas escolas, uma na zona rural e outra no perímetro urbano da cidade de Ceilândia, que fica na periferia do DF, a $33 \mathrm{~km}$ do centro de Brasília. Tal escolha não foi ao acaso. A ideia era entender se tais discursos de subjugação - se ocorrem - chegam da mesma forma para os públicos distintos da zona rural e urbana. Uma das escolas fica no Sol Nascente, região de vulnerabilidade social e baixo nível socioeconômico, e que tem apenas essa instituição pública como o único braço do Estado que alcança a população. A outra, fica na zona rural da mesma cidade satélite, Ceilândia, sendo uma das escolas do campo da cidade em questão. São realidades bem específicas por fazerem parte de locais diferentes dentro da mesma cidade. A primeira recebe estudantes que vivem, em sua maioria, em situação precária, tanto social quanto economicamente. É uma comunidade com altos índices de violência, que acabam se manifestando do lado de fora e do lado de dentro dos muros da escola, como facilmente se pode presenciar. A segunda recebe estudantes da zona rural, que são ou filhos dos donos das chácaras que produzem grande parte dos alimentos consumidos pelos moradores de Brasília ou são filhos dos caseiros ou trabalhadores das chácaras. Em geral, estudantes envolvidos com a produção agrícola.

O recorte aqui focalizado, no entanto, se apoia numa reflexão provocada por um dos temas que ressaltou na fala de cinco meninas e um menino, estudantes apenas da escola da zona urbana, por dois motivos: o primeiro, por necessidade da limitação do corpus - que acabou se revelando maior do que o esperado - e o segundo, talvez mais relevante, por apresentar relatos preocupantes relacionados ao que se quer verificar acerca do silenciamento das estudantes e discursos de subjugação. São dados gerados por meio de entrevistas semiestruturadas, em que a pesquisadora utilizou um gravador para registrar o áudio. Cada um teve um tempo livre para responder a algumas perguntas, previamente preparadas, mas que no decorrer da conversa, tiveram a possibilidade de sofrer modificações e ampliações, dependendo do engajamento dos colaboradores durante a entrevista. Tal procedimento encontra respaldo em pesquisas qualitativas que se orientam por dados de comportamento (cf. FLICK, 2009). Dentro da pesquisa mais ampla, este recorte destaca falas sobre um tópico que se salientou nos dados gerados, predominantemente por meninas que se sentiram à 
vontade - provavelmente pela conversa com outra mulher - para expor suas opiniões a respeito de alguns comportamentos na escola. A fala do menino mostra a contraparte da fala das meninas.

O artigo está estruturado em quatro seções, além desta contextualização: embasamento teórico, metodologia, discussão e análise dos dados (que são compostas por excertos de falas geradas pelas entrevistas). O embasamento teórico é predominantemente advindo da Análise de Discurso Crítica, representada aqui por Fairclough (2001), Pedro (1998) e Van Dijk (2008). Além de uma síntese da análise dos dados, a seção de considerações finais apontará as contribuições deste trabalho para os estudantes e a comunidade. Diálogos com Bourdieu (1989 e 2002), Spivak (2018) e Bauman (2005) contribuem para as categorias analíticas de violência simbólica, silenciamento e identidade.

\section{Embasamento Teórico}

A pesquisa é de natureza qualitativa e etnográfica, em que a pesquisadora insere-se no ambiente da coleta dos dados (ANGROSINO, 2009), e a análise das categorias analíticas, norteada por fundamentos da Análise de Discurso Crítica (ADC), dialoga com noções de poder, identidade, violência simbólica - que serão objeto de seções em destaque - e modos de operação da ideologia, principalmente com alguns dos modos de operação propostos por Thompson (2002): 1. Legitimação - torna as relações de dominação legítimas e dignas de apoio; categoria: narrativização. 2. Unificação - leva os indivíduos a pensarem que fazem parte de uma unidade quando, na verdade, não fazem; categorias: estandardização ou padronização. 3. Fragmentação - consiste em dividir um grupo que poderia ser uma ameaça ao poder dominante, pois será mais fácil dominá-los se estiverem separados; categoria: diferenciação. 4. Reificação- transforma um fato histórico transitório em permanente, retirando assim a importância histórica daquele momento; categoria: naturalização.

Secundariamente, alguns conceitos auxiliares ligados à comunicação não verbal e à subalternidade também auxiliarão nas análises, mas, pela necessidade de limites do artigo não passarão por reflexões mais aprofundadas. Nesta delimitação, tomamos emprestado de Gayatri Spivak o conceito de subalternidade, mesmo não desconhecendo muitas outras possibilidades de tratar o tema: de maneira geral, classes subalternas são categorias alijadas do poder, mesmo compostas por sujeitos heterogêneos.

\subsection{Análise De Discurso Crítica}

Para Pedro (1998, p. 25) um dos objetivos da Análise do Discurso Crítica é o de "analisar e revelar o papel do discurso na (re) produção da dominação [...] que resulta em desigualdade social 
[...] que deriva da diferenciação e discriminação de classe, de raça, de sexo e de características étnicas."

Nessa perspectiva, discutir o tema proposto por este artigo - qual seja, modos como as identidades femininas são silenciadas pela hegemonia masculina e seus discursos de subjugação não é apenas um objetivo de pesquisa, é também dever social. Levantar tal discussão, aparentemente óbvia para determinados grupos que já discutem as questões apresentadas, mas tão nova para tantos outros que a creem invisível, é criar também a possibilidade de ali iniciar um incômodo que poderá levar a uma mudança de discurso e de possíveis transformações. Certamente, é para estes que essas provocações se tornam mais relevantes.

Para estudos que consideram a performatividade da língua, não apenas para a Análise de Discurso Crítica, ações linguísticas - ou discursivas - estão no cerne da estruturação da sociedade, como nos mostram Levinson, (2007), Austin (1962) ou Rajagopalan (2010). Nessa linha, diz-nos Jacob Mey (2001, p. 27): “as vozes dos humanos são os instrumentos constitutivos sobre os quais se funda, em última instância, a orquestração da sociedade.” Nessa perspectiva, para entender a sociedade, compreender, interpretar e desvelar o que está posto nas práticas discursivas é também função da Análise do Discurso Crítica (cf. FAIRCLOUGH; FAIRCLOUGH, 2012).

Van Dijk (2008, p. 19) aponta:

Análise do Discurso é caracterizada como crítica porque toma posições; descreve explicitamente seu posicionamento e não os nega nem os dissimula; dirige-se a temas ou a problemas sociais, principalmente os vivenciados por grupos dominados; examina os mecanismos sociais, históricos, políticos e culturais que sustentam a reprodução do poder, principalmente as ideologias que alimentam, reproduzem ou legitimam o poder; aplica-se interdisciplinarmente a fenômenos sociais, políticos e culturais. Esses pontos resumem a flexibilidade de aplicação prática da ADC, que deve ser aplicável e gerar efeitos, como a resistência à ideologia dominante.

Pesquisas sobre grupos minoritários ou dominados são de grande interesse para a ADC, pois, ao estudar, clarear e tornar acessíveis, ao grupo dominado, reflexões para que este, em dado contexto e momento, comece a compreender e interpretar os comportamentos e ideias de seu interlocutor, possibilita-lhe ser capaz de rejeitar e contestar o que lhe serve de instrumento de subjugação. Ainda que o interlocutor ou a interlocutora esteja em posição de poder, o grupo dominado pode, assim, modificar a forma com a qual se relaciona com o seu dominador, quebrando o ciclo de dependência e - quem sabe - de invisibilidade e dominação. Como referencial teórico, a ADC analisa o objeto apresentado, os discursos e suas consequências, e desvela como a rede de atores sociais neles situados se constitui; utiliza as categorias analíticas para contribuir para uma melhor compreensão do mundo, dando condições para a modificação das práticas sociais. 
Por isso, a ADC concentra-se, principalmente, nos problemas sociais. Segundo Pedro (1998, p. 22), "os analistas críticos do discurso pretendem mostrar o modo como as práticas linguísticodiscursivas estão imbricadas com as estruturas sociopolíticas, mais abrangentes, de poder e dominação."

\subsection{Discurso e poder - do poder ao abuso de poder (dominação) nas relações escolares}

Para Fairclough (2001), é preciso considerar o que é o discurso já que ele é, ao mesmo tempo, estruturante e estruturado pelos processos sociais: não é apenas um fenômeno linguístico, mas também social. Assim,

O discurso contribui para a constituição de todas as dimensões da estrutura social que, direta ou indiretamente, o moldam e o restringem: suas próprias normas e convenções, como também relações, identidades e instituições que lhe são subjacentes. O discurso é uma prática, não apenas de representação do mundo, mas de significação do mundo, constituindo e construindo o mundo em significado. (FAIRCLOUGH, 2001, p. 95).

A par dessa "significação do mundo" caracterizadora do discurso como prática, também para Mey (2001, p. 27, grifo nosso) linguagem e sociedade não se desvinculam: "como personagens sociais e agentes, os humanos 'inventam' e estruturam a maneira como querem viver, mas também estão sujeitos às suas próprias criações."

Como os discursos são gerados no meio social, estão intimamente imbricados na construção de todos os âmbitos da estrutura social. Discursos são, antes de tudo, práticas, são modos de agir. São formas de agir e agir para tudo. Agir para o mundo e agir para o outro. Ao mesmo tempo, são formas de agir sobre os próprios discursos. Por isso, os discursos tanto revelam quanto plasmam modos de ser. Nesse âmbito, o sociólogo francês Pierre Bourdieu (1989 e 2002) bem destacou que a violência também se exerce por meios simbólicos, como a linguagem, já que "as relações de comunicação linguística são relações de força simbólica [...]; elas é que explicam porque determinados falantes exercem poder e domínio sobre outros” (SOARES, 1986, p. 56). Spivak (2010, p. 41) dá como exemplo de violência "o projeto, vasto e heterogêneo de se constituir o sujeito colonial como Outro". Nesse "apagamento" da subjetividade, manobra uma força de violência simbólica.

Para Fairclough (2001), são três as funções que prevalecem e formam o discurso. Três características da ação constitutiva do discurso: a identitária, que diz respeito à posição do sujeito dentro das práticas sociais; a relacional, que analisa a relação entre os sujeitos; e a ideacional, que verifica como os discursos se inter-relacionam com o sujeito. 
Nesta vertente teórica, as assimetrias sociais que geram o poder sobre o Outro podem ser estabelecidas de inúmeras formas e uma delas é pelo discurso. A dominação pode se dar por explícita violência verbal, mas, por vezes, é produzida nos textos e nos falares de modo tão sutil que se apresenta como natural e aceitável. Ocorre que o grupo que se sobrepõe sabe que já conseguiu tal poder, não só no campo das palavras e ações, como no das ideias. Nem sempre o grupo que domina, necessariamente, precisa ser economicamente superior, principalmente, se o que é posto for legitimado, culturalmente, por séculos. Segundo Pedro (1998, p. 26):

O poder envolve controle, nomeadamente de um grupo sobre outros grupos. Além do recurso à força para o exercício do controle da ação, o poder, hoje, utiliza formas muitas vezes bastante eficazes, através da persuasão, da dissimulação ou da manipulação.

Com facilidade, os comportamentos, atitudes e discursos vão extrapolando limites sociais e ideológicos. Segundo Van Dijk (2008, p. 29), abuso de poder é o uso ilegítimo do poder.

O abuso de poder, então, significa a violação de normas e valores fundamentais no interesse daqueles que têm o poder e contra os interesses dos outros. Os abusos de poder significam a violação dos direitos sociais e civis das pessoas. Na área do discurso e da comunicação, isso pode significar o direito de ser bem ensinado e educado, de ser bem informado etc.

Na inter-relação entre as três características constitutivas da ação discursiva - nos termos de Fairclough (2001), nas práticas sociais e discursivas, que abrigam abusos de poder e invadem limites de constituição identitária, sobressai a violência simbólica de Bourdieu (2002) - objeto destas reflexões.

\subsection{Identidade}

Para uma breve noção do que se toma aqui a partir de conceitos de identidade, recorremos ao que diz Bauman (2005), aprofundando o que traz Fairclough (2001), que localiza o sujeito dentro das práticas sociais. Para Bauman (2005), eu sou aquilo que o outro não é. Se o outro é o que eu não sou, seriam as mulheres apenas o que os homens não seriam? Como se constrói a identidade "permitida" para as mulheres?

Em nome de uma organização das relações sociais - em qualquer grupo ou comunidade existe uma pressão para identidades pré-definidas. A liberdade de escolha, não é, de verdade, uma liberdade totalmente livre. É uma liberdade entre algumas escolhas previamente agendadas, uma liberdade controlada pela organização social e cultural, uma liberdade vigiada. Quando alguém destituído de poder apresenta uma questão ou uma opção que não seja hegemônica, sofre uma sanção. 
É o que Thompson (2002, p. 87) chama de expurgo do outro. "O excluído é marcado negativamente." Tal expurgo não parece uma relação simples na sociedade. Ou uma mera relação de causa e consequência. É, antes de tudo, uma relação constitutiva das práticas sociais - e das práticas discursivas, como se conclui a partir da menção já feita a Fairclough (2001): são práticas que não apenas representam, mas também dão significação ao mundo. Por isso o expurgo se amplia também para agendamentos prévios de papeis sociais a que se veda o acesso a partir de certas posições. E por também serem significação de mundo, práticas discursivas acabam reproduzidas também por sujeitos excluídos e taxados como Outro.

Por isso, cada um de nós, segundo Hall (2005), é levado, mesmo de forma inconsciente, a assumir certas posições de sujeito, seja motivado por questões culturais, seja por alguma posição institucional ou ideológica. Em um mundo tradicionalmente definido pela caracterização biológica do que seja homem e do que seja mulher, ao se nascer mulher assumem-se papeis ou lugares prédefinidos, inculcados social e culturalmente, mesmo que sejam danosos ou prejudiciais, psicológica e moralmente. A primeira questão que se coloca é: mas e se ela não estiver nesse lugar, em qual estará? Ou: se eu não estiver nesse papel, em qual estarei? Qual outro espaço lhe/me é confiado, ou previsto pelo grupo ou pela cultura? E se ela/eu tiver a oportunidade de ocupar outros espaços, é/sou considerada apta para assumir outros papeis? Não tem a mulher, assim como o homem, necessidade de sujeição à identidade, como questiona Hall? Ao levantar tantos questionamentos e dúvidas que circundam o "ser mulher" talvez possamos começar a entender o motivo pelo qual as relações sociais e discursivas tornam difícil para as mulheres cederem às suas próprias vontades, ou perceberem que estão em uma relação de subjugação, pois assumem as marcas identitárias que o outro lhes impõe e, inconscientemente, agem em nome da manutenção dessa identidade, mesmo que esta não seja definitiva.

\subsection{Poder simbólico e violência simbólica}

Já vimos que a violação dos direitos sociais, a invasão dos limites identitários do outro é, para Van Dijk (2008), abuso de poder. Para Bourdieu (1989), a violência simbólica é o meio de exercício do poder simbólico. "O poder simbólico é, com efeito, esse poder invisível o qual só pode ser exercido com a cumplicidade daqueles que não querem saber que lhe estão sujeitos ou mesmo que o exercem" (BOURDIEU, 1989, p. 7). Como esse poder se manifesta, segundo Bourdieu (1989), pelos sistemas simbólicos - língua, arte, ciência, mito e religião - é por eles que o poder simbólico toma corpo e se espraia de forma sutil como uma folhagem que se espalha pelo tronco de uma árvore. 
Embora na violência simbólica não se considere que haja um corpo agredido fisicamente; os prejuízos por ela causados, tanto de ordem moral quanto psicológica, são também sérios, longevos e danosos. Muitos valores, hábitos e comportamentos são impostos pela força do poder dominante, sem que seja necessário recorrer à violência física. Contudo, tal abuso de poder cria situações nas quais o indivíduo que sofre a violência simbólica sente-se inferiorizado e coagido sendo, por vezes, incapaz de reagir. A isso podemos chamar subjugação. Em muitos casos, apenas por sua condição de ser mulher, as mulheres sentem-se assim, presas a valores e crenças que as arrastam para a invisibilidade: acabam por aceitar e acreditar na certeza criada, social e discursivamente, que, realmente, não há outra forma de ser e viver.

Ao longo da pesquisa, torna-se perceptível que os discursos de subjugação se fazem presentes também na escola, pois não há como separar ou isolar as relações que os estudantes vivem em sociedade das que eles praticam no ambiente escolar. Identidades são construídas em todos esses espaços. As adolescentes, em geral, recebem diretamente o peso e a responsabilidade de características identitárias que lhes são impostas, mas, mesmo quando insatisfeitas ou incomodadas, não têm visão crítica, tampouco discernimento para interpretar e avaliar o que está sendo dito.

$\mathrm{Na}$ relação de interação entre professor/a e aluno, o/a professor/a, um dos agentes responsáveis pelo processo educativo, tem a possibilidade de colocar em pauta algo tão concreto e começar a levantar o véu sobre as práticas que ali ocorrem, diariamente, e que os estudantes - tanto homens quanto mulheres - não se dão conta. Estão todos inseridos, são causa e consequência, de uma cultura que se molda por padrões de imposição da prática social que subestima a capacidade feminina.

\subsection{Subalternidade}

Nas práticas sociais e discursivas que dão prevalência aos valores masculinos sobre os femininos, ressalta o que Spivak (2010) chama de relação de subalternidade. Para ela, o termo subalterno requer, de início, duas reflexões. A primeira é que o subalterno ou a subalterna é aquele/a cuja voz, por algum motivo, não pode ser ouvida. E, por extensão, tem sua atuação na sociedade cerceada. A segunda é que nenhum ato de resistência pode ocorrer em nome do subalterno ou da subalterna sem que esse ato esteja ligado a um discurso hegemônico, já que seria a voz de um/a intelectual, por exemplo, daquele/a que julga poder falar pelo outro. Neste caso, em princípio, o outro reproduziria discursos embasados nas estruturas de poder e opressão, pois manteria o subalterno ou a subalterna silenciado/a, sem voz. Não seria oferecido a este um espaço ou uma posição para que não só pudesse falar, mas que fosse também ouvido. Para ela, "não se pode falar pelo subalterno, mas 
pode-se trabalhar "contra" a subalternidade, criando espaços nos quais o subalterno possa se articular e, como consequência, possa também ser ouvido.” (SPIVAK, 2010, p. 14).

Nesse cenário, se o discurso do subalterno ou da subalterna é eliminado, silenciado por nem sequer ser ouvido, a mulher que não percebe ou nem sabe que lhe está sendo imposta uma identidade de dominada na sociedade ocupa o polo subalterno da relação social. De modo simplificado, pode-se dizer que a mulher subalterna ocupa uma posição no mais baixo grau da subalternidade, pois, "Se no contexto de produção colonial, o sujeito subalterno não tem história e não pode falar, o sujeito subalterno feminino está ainda mais profundamente na obscuridade. ” (SPIVAK, 2010, p. 15).

\section{ESTUDO DA ESCUTA DE FALAS SILENCIADAS}

A pesquisa na escola ocorreu no período de agosto a dezembro de 2018. O primeiro momento na escola foi o de apresentação da pesquisa, em reunião com os professores e depois em seis salas de aula, com, no mínimo, quatro encontros com cada turma do $9^{\circ}$ ano para discussão do assunto. Os estudantes, em um total de 260 somando todos os $9^{\circ}$ s anos, foram convidados a participar de uma entrevista semiestruturada individual e receberam um termo de consentimento livre e esclarecido a ser preenchido. Os que, de fato, se interessaram e apresentaram a devida autorização, por serem menores, responderam a algumas questões acerca do tema apresentado previamente: "Silenciamento da mulher: consciência crítica e discursos de subjugação na escola”, pesquisa de mestrado de uma das autoras.

Dentre todos os que se dispuseram a colaborar com esta pesquisa, seis entrevistas compõem o corpus recortado neste artigo. As entrevistas foram realizadas no mesmo turno de estudo dos estudantes ouvidos para evitar que tivessem de voltar para a escola no contraturno. Em todas as falas dos adolescentes, cinco garotas e um garoto, ficam evidentes as estratégias do discurso embutindo avaliações negativas que indicam caminhos, limitam espaços, estabelecendo assim, relações de poder. Excertos que mostram isso mais salientemente são apresentados a seguir, na seção de discussão, análise e interpretação dos dados. Para preservar as identidades dos colaboradores, apenas iniciais e idades são utilizadas. Serão apresentados a seguir alguns excertos das entrevistas com os colaboradores.

\section{DisCUSSÃo}

Os excertos das entrevistas com os seis colaboradores mostram de que modo as suas falas apontam para o que foi sintetizado anteriormente. 
O primeiro relato é do colaborador MS, de 16 anos, sobre como ele se relacionava com sua namorada e exigia que ela se vestisse. Deixa claro o modo como ele exerce o poder na relação de dominação sobre ela.

\section{Excerto 1 (MS, de 16 anos)}

“...eu não gosto dos outros olhando pro que é meu."

\begin{tabular}{|c|c|l|}
\hline Pesquisadora & 1 & Há3 direitos iguais entre mulheres e homens hoje na nossa sociedade? \\
\hline MS & 2 & Não muito. \\
\hline Pesquisadora & 3 & Pode dar um exemplo? \\
\hline MS & 4 & Porque tipo, pelo... tipo assim... não que tem, mas sim pelo homem, o \\
\hline & 5 & homem acha que a mulher ela tem que ficar em casa e não tem direito de \\
\hline & 6 & sair com um short curto, essas coisas... \\
\hline Pesquisadora & 7 & Você acha que esse pensamento do homem se dá pelo quê? O que faz o \\
\hline & 8 & homem ter esse pensamento? Ele acha que ele é mais importante, que ele \\
\hline & 9 & tem mais direito? De onde vem isso? \\
\hline MS & 10 & Não sei, acho que é também... tipo... vou falar de mim mesmo sabe... eu.... \\
\hline & 11 & namorava e aí tipo eu não gostava que minha namorada sá́sse com tipo \\
\hline & 12 & aqueles shortzinhos... aí eu falava: amor, troca de roupa! Eu não tô \\
\hline & 13 & gostando que os outros ficam olhando pra você e eu não gosto dos outros \\
\hline & 14 & olhando pro que é meu, por isso \\
\hline Pesquisadora & 15 & E ela trocava? \\
\hline MS & 16 & Sim. \\
\hline Pesquisadora & 17 & E sua fala: “... não gosto dos outros olhando pro que é meu.... traz uma \\
\hline & 18 & ideia de posse. Vocế acha isso saudável? \\
\hline MS & 19 & Não, não é, mas assim... tipo... por causa que eu falava que era meu por \\
\hline & 20 & causa que eu conquistei ela, demorou um pouquinho, mas eu consegui. \\
\hline Pesquisadora & 21 & Estão juntos? \\
\hline MS & 22 & Separados. \\
\hline Pesquisadora & 23 & E ela era sua? \\
\hline MS & 24 & Não. \\
\hline Pesquisadora & 25 & Você acha que essa ideia de que a mulher é posse sua, de que você é dono \\
\hline MS & 26 & dela e tem o direito de exigir que ela troque de roupa vem do quê? \\
\hline & 27 & Ah... sei lá, vem de mim, eu vejo na rua, você vê isso muito na rua. \\
\hline & & \\
\hline
\end{tabular}

Segundo Van Dijk (2008), o poder envolve controle; e MS, ao dizer: "amor, troca de roupa! " (linha 12), deixa claro o controle que ele já exercia sobre os comportamentos e hábitos de sua namorada, enquanto o homem que manda, que decide o que a outra pessoa, no caso a mulher, poderá ou não fazer. Mesmo que em tom carinhoso, como aparentou ser, mesmo com justificativas aparentemente legitimadas, o suposto "cabeça" da relação, aquele que tem sempre o controle da situação, é quem dita comportamentos. Uma das categorias de análise de Thompson (2002) é a legitimação, o modo de operação ideológica que torna as relações de dominação legítimas e dignas

\footnotetext{
${ }^{3} \mathrm{O}$ verbo haver pode dar a entender que tal pergunta afirmava que existiam direitos iguais entre homens e mulheres. Uma solução seria a de iniciar a frase com "sobre direitos de mulheres e homens". O fato ocorre no excerto citado e em outro seguinte e foi observado depois de a entrevista ter sido dada, estando a pesquisadora ciente da questão.

${ }^{4}$ A pesquisadora, ao indagar diretamente se o colaborador achava tal conduta saudável, quis saber de fato o motivo que o levou ou os motivos que o levaram a ter tal atitude e não quis, em momento algum, induzir a resposta para o sim ou não, tanto é que a resposta, na sequência, é diferente de apenas uma afirmação ou negação.
} 
de apoio. Como justificativa para essa legitimação, MS diz: "eu falava que era meu por causa que eu conquistei ela, demorou um pouquinho, mas eu consegui. " (linhas 19 e 20). Mais uma vez, vê-se aí o reforço da posição do homem impondo, por via do comportamento ao vestir, um lugar de apassivação na relação: por ele ter demorado muito tempo para conquistá-la, ele passaria, após o namoro iniciado, a ter o direito de determinar o que ela poderia ou não fazer. A justificativa para a legitimação é reforçada pela naturalização, em sua última fala: "vem de mim, eu vejo na rua, você vê isso muito na rua" (linha 27). De acordo com Thompson (2002), a naturalização opera com a justificativa de que é válido porque todos ou quase todos assim o fazem. Se "você vê na rua", se tanto pensam ou agem assim, por que eu não deveria pensar, ou agir assim? Que motivo não me levaria a manter a mesma prática? É assim que práticas culturais e históricas vão se naturalizando na ideologia da dominação.

Para Bourdieu (2002, p. 31), no livro A dominação masculina,

Se a relação sexual se mostra como uma relação social de dominação, é porque ela está construída através do princípio de divisão fundamental entre o masculino, ativo, e o feminino, passivo, e porque este princípio cria, organiza, expressa e dirige o desejo - o desejo masculino como desejo de posse, como dominação erotizada e o desejo feminino como desejo da dominação masculina, como subordinação erotizada, ou mesmo, em última instância, como reconhecimento erotizado da dominação.

Há, desse modo, para o homem, certa erotização no desejo de dominar. O que está também por trás da fala do colaborador MS (mesmo que ele possa não ter clareza disso) é que, ao agir assim, ele está dando seguimento à sensação humana de que dominar produz uma sensação quase erotizada para o homem. Bourdieu ainda vai além ao dizer que a força da dominação masculina é legitimada por uma "natureza biológica que é, por sua vez, ela própria uma construção social naturalizada" (BOURDIEU, 2002, p. 33). MS está, nas suas falas, reivindicando sua identidade masculina em um mundo em que isso representa dominação das identidades femininas.

Em várias outras entrevistas, do mesmo corpus, é frequente os relatos apontarem para o fato de os meninos acharem normal pegar nos corpos das meninas, sem a permissão delas, simplesmente por serem homens e de acharem que as práticas sociais brasileiras, que constituem e em que são constituídas suas identidades, lhes dão esse direito, ou poder, de controlarem as mulheres ou de se sentirem superiores a elas no tocante à força de sua suposta posição. Também no excerto 2, da estudante MC, de 15 anos, aparece a relação de dominação, única e exclusivamente por serem homens. 


\section{"Me chamaram de chata porque não deixei pegar na minha bunda."}

\begin{tabular}{|c|l|l|}
\hline Pesquisadora & 1 & Já se sentiu desrespeitada na escola por ser mulher? \\
\hline MC & 2 & Já! \\
\hline Pesquisadora & 3 & Quando? \\
\hline MC & 4 & Quando um menino pegou na minha bunda e eu não deixei. Muitas \\
\hline & 5 & vezes me chamaram de chata, né \\
\hline Pesquisadora & 6 & Quem te chamou de chata? \\
\hline MC & 7 & Um menino. \\
\hline Pesquisadora & 8 & Qual foi a reação dele quando você barrou? \\
\hline MC & 9 & Não... ficou olhando com a cara assim... e eu não, não pode pegar, \\
\hline & 10 & não é assim. \\
\hline Pesquisadora & 11 & E aí você foi chamada de chata? \\
\hline MC & 12 & Sim. Me chamaram de chata porque não deixei pegar na minha bunda \\
\hline
\end{tabular}

A reação de $\mathrm{MC}$, ao negar o direito ao menino de tocar em seu corpo, provoca uma contrarreação de recriminação ("chata"), como se fosse ela a infringir normas sociais e a ultrapassar limites de relação social. Zanello $(2018$, p. 192) chama a atenção para "O que se inscreve para os homens é justamente a não aprendizagem da renúncia sexual e da frustração de seus desejos (para muitos, tratava-se - e trata-se até hoje - de um direito")".

Logo, os homens são legitimados social e culturalmente a não reprimir os seus desejos, mesmo que esses envolvam algum tipo de invasão ao espaço das mulheres, uma agressão a elas .

Excerto 2 ( MC, 15 anos) - segunda parte "Ele dizia que ele era o alfa."

\begin{tabular}{|c|c|l|}
\hline Pesquisadora & 1 & Alguém já disse que você era inferior e tinha de obedecer por ser menina? \\
\hline \multirow{5}{*}{ MC } & 2 & Eu tive um namorado que ele achava isso. Mas por ver isso, tipo... hoje em \\
\hline & 3 & dia muitos homens matam mulheres e tal... aí eu terminei com ele por \\
\cline { 2 - 3 } & 4 & perceber que ele era assim... que achava que mandava em mim, por ser \\
\cline { 2 - 3 } & 5 & homem e ser mais forte. Ele dizia que ele era o alfa. Tipo eu que deveria \\
\hline Pesquisadora & 7 & Ebedecer ele porque ele que mandava. \\
\hline MC & 8 & É não, tipo... ele brigava muito, era muito ciumento e não deixava eu usar \\
\hline & 9 & algumas coisas... e até mesmo me arrumar pra vim pra escola, não deixava \\
\hline Pesquisadora & 10 & Ele controlava até seu modo de vestir, então? \\
\hline MC & 11 & Sim, ele controlava o meu modo de vestir, ele dizia que ia clonar o meu \\
\hline & 12 & WhatsApp no dele pra ele saber com quem eu tava conversando... era \\
\cline { 2 - 3 } & 13 & muita.... (suspiros) \\
\hline Pesquisadora & 14 & Como eram as atitudes dele? Ele chegou a ter uma atitude assim de dizer... \\
\hline & 15 & não, você não vai fazer isso, te proibir? \\
\hline MC & 16 & Sim, quando eu queria ir pra igreja, tipo é longe, aí eu ia com o meu líder \\
\hline & 17 & e meu líder por ser jovem ele não deixava eu ir, até porque eu me afastei \\
\cline { 2 - 3 } & 18 & da igreja... agora que eu tô voltando por ter terminado com ele. \\
\hline Pesquisadora & 19 & Vocês namoraram quanto tempo? \\
\hline MC & 20 & 5 meses. \\
\hline Pesquisadora & 21 & Qual a idade de vocês dois enquanto vocês namoravam? \\
\hline MC & 22 & Eu tinha 15 e ele 17. \\
\hline
\end{tabular}


Na segunda parte do excerto de MC, fica explícita a relação de dominação mencionada por Bourdieu (1989). Isso se dá por discurso que pode ser analisado, principalmente, pela categoria da fragmentação, de Thompson (2002). Segundo essa categoria, separa-se alguém, ou algo, de um grupo, para se manter controle sobre o isolado. Ao isolar a namorada, ao tentar mantê-la longe do grupo social de que ela participava, e ao querer monitorá-la via celular, o namorado exerce sua dominação masculina, apoiando-se na força de que será mais fácil dominá-la se ela estiver separada de seu grupo, e enfraquecida. Fica clara, nas falas que seguem, a intenção do namorado de $\mathrm{MC}$ de exercer o controle que se efetivava em ações: "ele controlava o meu modo de vestir, ele dizia que ia clonar o meu WhatsApp no dele pra ele saber com quem eu tava conversando" (linhas 11 e 12) e "quando eu queria ir pra igreja, tipo é longe, aí eu ia com o meu líder e meu líder por ser jovem ele não deixava eu ir, até porque eu me afastei da igreja" (linhas 16, 17 e 18). O relato mostra ainda como ele se sentia com o poder para controlar, como apresenta Van Dijk (2008) ao caracterizar abuso de poder. Para interpretação da assertiva "...que achava que mandava em mim, por ser homem e ser mais forte. Ele dizia que ele era o alfa" (linhas 4 e 5), podemos dizer, com Zanello (2018), que ele lançou mão do dispositivo da eficácia masculina, de sua virilidade de macho alfa.

Muitas meninas relataram o quanto se sentem acuadas e obrigadas a seguirem padrões préestabelecidos na maneira de vestir, de falar ou de sentar para não serem rotuladas de promíscuas ou vadias. Vejamos o que diz Bourdieu (2002, p. 38-39):

\footnotetext{
A educação elementar tende a inculcar maneiras de postar todo o corpo, ou tal ou qual de suas partes... a moral da honra masculina pode ser resumida em uma palavra, cem vezes repetida pelos informantes, qabel, enfrentar, olhar de frente e com a postura ereta. ... do mesmo modo a submissão feminina parece encontrar sua tradução natural no fato de se inclinar, abaixar-se, curvar-se, de se submeter nas posturas curvas, flexíveis, e na docilidade correlativa que se julga convir à mulher. Outras posturas estão carregadas de uma significação moral (sentar-se de pernas abertas é vulgar, ter barriga é prova de falta de vontade etc.). Como se a feminilidade se medisse pela arte de "se fazer pequena" (o feminino, em berbere, vem sempre em diminutivo), mantendo as mulheres encerradas em uma espécie de cerco invisível... enquanto os homens tomam maior lugar com seu corpo, sobretudo em lugares públicos.
}

Na esteira desse pensamento, as mulheres sofrem um confinamento simbólico e até os dias de hoje elas são medidas pela sua vestimenta. É o que podemos acompanhar no excerto 3, da estudante YG, de 15 anos:

Excerto 3 (YG, 15 anos) - primeira parte

\section{“... a própria direção pede pras garotas vestirem de certo modo pra não chamar a atenção dos garotos."}




\begin{tabular}{|c|c|l|}
\hline Pesquisadora & 1 & Você acredita que devido à escola ser um ambiente em que meninos e meninas \\
\hline \multirow{2}{*}{ YG } & 2 & dividam o mesmo espaço não exista mais diferenças de nenhuma ordem na \\
\cline { 2 - 4 } & 3 & convivência e direitos entre eles? \\
\hline & 4 & Ah sim... bem que poderia, mas realmente dá pra perceber a diferença ainda tanto \\
\hline \multirow{2}{*}{ Pesquisadora } & 5 & em modos de tratar, em atos, em jeito de falar como a própria direção pede \\
\hline YG & 7 & pras garotas vestirem de certo modo pra não chamar a atenção dos garotos. \\
\hline & 9 & Então, nem sempre tem essa igualdade na escola. \\
\hline & 10 & EÃo. Os garotos nunca foram pedidos de se vestirem de tal maneira pra não \\
\cline { 2 - 4 } & 11 & short na quadra não importa o tamanho, porque não querem que chamem \\
\cline { 2 - 4 } & 12 & a atenção dos garotos. \\
\hline Pesquisadora & 13 & E aí vocês usam o quê? \\
\hline YG & 14 & A gente tem de usar ou legging ou aquelas calças de moletom grandes porque \\
\hline & 15 & é como se a culpa fosse nossa se eles olharem. \\
\hline Pesquisadora & 16 & Você acha que isso vem de onde? \\
\hline YG & 17 & Cara, isso vem desde o berço, porque a sociedade foi criada desse jeito, \\
\hline & 18 & como se, se você for mulher tem que fazer o que for pra se agradar o homem \\
\hline & 19 & pra você não ser vista com maus olhos porque se acontecer alguma coisa \\
\hline & 20 & a culpa é de quem? É nossa diante deles. \\
\hline Pesquisadora & 21 & Então é a mulher que tem de se cuidar e se resguardar e o homem não? \\
\hline YG & 22 & Sim, mais uma vez ele não tem essa responsabilidade sobre nada, nunca tem. \\
\hline
\end{tabular}

Um fato curioso no excerto da adolescente YG é o posicionamento que a própria escola incentiva, como instituição representante da hegemonia social: preservar a continuidade de uma cultura de dominação masculina, em que as mulheres são responsabilizadas por sofrer algum ataque por parte dos homens. Por isso, a ela é ensinado desde cedo que não deve usar determinados tipos de roupa para não provocar reações de reprimenda ao seu comportamento. De acordo com Thompson (2002), pela categoria da unificação, as pressões ideológicas levam os indivíduos a pensarem que fazem parte de uma unidade quando, na verdade, não fazem. Mesmo fazendo parte do grupo “feminino", a padronização, ou estandardização, que se espera de YG acaba por ser incorporada ao seu ponto de vista. Suas conclusões comprovam isso: "A gente tem de usar ou legging ou aquelas calças de moletom grandes porque é como se a culpa fosse nossa se eles olharem.” (linhas 14 e 15). Do mesmo modo "Sim, mais uma vez ele não tem essa responsabilidade sobre nada, nunca tem. " (linha 22). Mas, mesmo compreendendo, que estão sofrendo controle indevido, as adolescentes não sabem - ou não têm instrumental - para reagir ao abuso de poder. Sofrem a pressão da rede social em que se constituem como sujeitos, em que constroem suas identidades.

\section{“... lugar de mulher é na cozinha e não soltando pipa."}

\begin{tabular}{|l|l|l|l} 
Pesquisadora & 1 & Você já foi tratada de maneira diferente por ser mulher? Se sim, como foi e
\end{tabular} 2 como se sentiu? 


\begin{tabular}{|c|c|l|}
\hline BS & 3 & Sim. Já ouvi... você não pode fazer isso porque você é mulher, não pode usar \\
\hline & 4 & essa roupa porque é mulher. Isso é coisa de macho, lugar de mulher é na \\
\cline { 2 - 3 } & 5 & cozinha e não soltando pipa. Já fui proibida de soltar pipa por ser mulher. \\
\hline
\end{tabular}

Como resultado do que Thompson (2002) classifica como fragmentação, a adolescente é excluída dos direitos de se comportar, ou se vestir, como quiser. A constatação de que existe assimetria no exercício do poder transparece na fala de BS, sem que ela explicite uma reação, seja no discurso, seja na prática social.

\author{
Excerto 5 (MF, 15 anos) \\ "Elas são moeda de troca."
}

\begin{tabular}{|c|c|l|}
\hline Pesquisadora & 1 & No ambiente escolar é possível perceber casos de meninas que se subjugam \\
\hline & 2 & aos meninos em troca de algo, como atenção, por exemplo? Já vivenciou \\
\cline { 2 - 3 } & 3 & algo parecido? Se sim, como se sentiu ou agiu a respeito? \\
\hline \multirow{2}{*}{ MF } & 4 & Sim. As namoradas dos “Zé droguinhas", elas fazem os que eles querem. \\
\hline & 5 & São namoradas de usuários, pessoas que vendem drogas aqui na escola. Elas \\
\hline \multirow{4}{*}{} & 6 & fazem muitas coisas em troca de droga... apanham... e se submetem às \\
\cline { 2 - 3 } & 7 & coisas. Ah... muitas coisas. Elas servem de aviãozinho, prostituição aqui na \\
\cline { 2 - 3 } & 8 & escola. Elas ficam no final do corredor e os meninos vão até elas em troca \\
\cline { 2 - 3 } & 9 & de drogas, sexo e dinheiro. Elas são moeda de troca. Parece que elas buscam \\
\cline { 2 - 3 } & 10 & lugar de destaque, lugar de poder. \\
\hline
\end{tabular}

Ressalta-se nessa fala de MF que o relato se refere a "elas", as "namoradas dos 'Zé droguinhas" (linha 4). Embora a posição crítica seja velada, fica explícita a comparação do comportamento criticado com a dos meninos que exercem o controle, a dominação: "parece que elas buscam lugar de destaque, lugar de poder." (linhas 9 e 10). Apesar de serem consideradas "moeda de troca" (linha 9), o comportamento das namoradas dos "Zé droguinhas" (linha 4) é o de quem "busca poder" (linhas 9 e 10); é a busca pela dominação, pelo controle, pelo abuso do poder. Para MF, a resposta ao que seria subjugação vem na narrativização de casos que presencia. Essa é uma categoria que legitima valores ideológicos.

Embora aqui se tangencie o tema da prostituição, não o abordaremos devido à delimitação do corpus, mas principalmente ao fato de não ter aparecido nos dados - embora seja mencionada a "moeda de troca" (linha 9) como valor simbólico do poder. 


\begin{tabular}{|c|c|c|}
\hline Pesquisadora & 1 & No ambiente escolar é possível perceber casos de meninas que se subjugam aos \\
\hline & 2 & meninos em troca de algo, como atenção, por exemplo? Já vivenciou algo \\
\hline & 3 & parecido? Se sim, como se sentiu ou agiu a respeito? \\
\hline \multirow[t]{6}{*}{ YG } & 4 & Sim. Tem muitos casos na escola até que é de conhecimento da direção, \\
\hline & 5 & dos professores, mas essa escola funciona como uma pequena sociedade. \\
\hline & 6 & A gente tem muita coisa, muita coisa mesmo que acontece aqui dentro até como \\
\hline & 7 & o caso de prostituição de alunas dentro da própria escola, mas é um assunto \\
\hline & 8 & que nem a direção não discute. Elas fazem isso às vezes nem em troca de nada \\
\hline & 9 & específico, só realmente por essa atenção. \\
\hline Pesquisadora & 10 & Você poderia falar, tem algum exemplo para dar? \\
\hline \multirow[t]{3}{*}{ YG } & 11 & Um exemplo até recente do que aconteceu, que uma aluna foi flagrada em \\
\hline & 12 & sala de aula fazendo "atos" com os alunos, mas no final isso não dá nada \\
\hline & 13 & pra eles porque é comum dentro das escolas isso \\
\hline Pesquisadora & 14 & Eu não entendi... fazendo atos? \\
\hline YG & 15 & É... "atos obscenos", "atos". \\
\hline Pesquisadora & 16 & O que você sentiu quando ficou sabendo? \\
\hline \multirow[t]{6}{*}{ YG } & 17 & Poxa... eu cheguei a me sentir desconfortável, porque na escola é a escola, cara... \\
\hline & 18 & é meio estranho ver isso. Até porque dá pra perceber que os alunos, os garotos \\
\hline & 19 & dessa escola, eles num tem aquele respeito todo por mulher. Eles tratam \\
\hline & 20 & como se fosse realmente um objeto. É tanto que já teve até competição \\
\hline & 21 & deles escreverem em folha sobre quem é a mais bonita, quem é a mais feia, \\
\hline & 22 & esse tipo de coisa. E a gente se sente desconfortável, né? \\
\hline \multirow[t]{2}{*}{ Pesquisadora } & 23 & Já teve de fazer algo que não queria para ser aceita pelo grupo ou pelos meninos? \\
\hline & 24 & Se sim, poderia dizer o que teve de fazer? \\
\hline \multirow[t]{4}{*}{ YG } & 25 & Já. Já tive de falar de assuntos que eu não queria. Já tive de fingir antes \\
\hline & 26 & ser alguém que eu não era. Falar sobre coisas que na real nem me agradavam. \\
\hline & 27 & Só que hoje eu sou muito diferente em relação a isso, eu sou mais, tipo eu \\
\hline & 28 & sou dona de mim, eu vou fazer o que eu quiser. \\
\hline Pesquisadora & 29 & Poderia dar um exemplo do que você já falou ou fez? \\
\hline \multirow[t]{5}{*}{ YG } & 30 & Tipo, assuntos que na maioria das vezes nem me interessavam, como esportes, \\
\hline & 31 & os garotos eles falam muito de garotas... se você ficar ali no meio você se sente \\
\hline & 32 & desconfortável de ouvir eles falando com aquela sexualidade toda sobre uma \\
\hline & 33 & pessoa que você até conhece. E você tem que ficar ali comentando como se \\
\hline & 34 & você realmente tivesse se agradando daquele assunto e no final das contas não é. \\
\hline \multirow[t]{2}{*}{ Pesquisadora } & 35 & Para ser aceita? \\
\hline & 36 & Pra ser aceita por eles. \\
\hline
\end{tabular}

O diálogo mostra que a tomada de consciência sobre as relações de abuso de poder que acontecem na escola não chega a ser suficiente para que YG reforce sua posição de identidade feminina: "Poxa... eu cheguei a me sentir desconfortável, porque na escola é a escola, cara... é meio estranho ver isso." (linhas 17 e 18). A continuidade mostra que a naturalização de falas e comportamentos acaba inicialmente por prevalecer, quando admite que já teve "de falar de assuntos que eu não queria. Já tive de fingir antes ser alguém que eu não era. Falar sobre coisas que na real nem me agradavam.” (linhas 25 e 26). Ao se tornar “dona de mim” (linha 28), YG assume identidade que resiste ao domínio e reconhece que o silenciamento de sua voz se dava, conscientemente, "para ser aceita por eles" (linha 36). Mesmo reconhecendo que "eles tratam como se fosse realmente um objeto" (linhas 19 e 20), sua reação era externada pelo silenciamento de sua identidade ao compactuar com assuntos que não eram de seu agrado. 
Nos últimos excertos fica claro que esse silenciamento é um aceite à subjugação e à subalternidade pelas quais passam as adolescentes na escola. De forma consciente ou não, elas são silenciadas em troca de um lugar de poder, mesmo que efêmero, ou simplesmente em troca de atenção. Vê-se aqui uma força simbólica do domínio por meio do silenciamento (cf. BOURDIEU, 1989 e 2002). Algumas vezes o silêncio das falas chega a um comportamento de quase anulação, como mostra o fragmento a seguir.

\section{Excerto 7 (VM, 14 anos)}

\section{"Porque vai continuar a mesma coisa. Não vai mudar nada, professora. Não vai mudar muita coisa."}

\begin{tabular}{|c|c|c|}
\hline \multirow[t]{3}{*}{ Pesquisadora } & 1 & Devido a escola ser um espaço compartilhado por meninos e meninas, você \\
\hline & 2 & diria que não há mais diferenças, de nenhuma ordem, na convivência e direitos \\
\hline & 3 & entre vocês? \\
\hline \multirow[t]{4}{*}{ VM } & 4 & Ainda há. Tem diferença. Tipo jogar bola, jogar totó, os meninos acham que a \\
\hline & 5 & quadra é só pra eles. Eles falam que a quadra é deles que é local de homem, \\
\hline & 6 & que o totó também é só deles, que é coisa de homem e que a mulher não pode \\
\hline & 7 & fazer. \\
\hline Pesquisadora & 8 & Mas vocês são proibidas de usarem a quadra? \\
\hline VM & 9 & Sim, pelos meninos \\
\hline \multirow[t]{2}{*}{ Pesquisadora } & 10 & E o que você e as suas colegas de sala fazem na aula de educação física \\
\hline & 11 & enquanto os meninos usam a quadra? \\
\hline VM & 12 & Fica sentada. \\
\hline Pesquisadora & 13 & Essa é a aula de educação física? \\
\hline VM & 14 & É. A nossa é. \\
\hline Pesquisadora & 15 & Você já tentou reclamar, levar o assunto para a direção? \\
\hline VM & 16 & Eu nunca tentei não. \\
\hline Pesquisadora & 17 & E as meninas da sua sala, já tentaram reclamar? \\
\hline VM & 18 & Não. \\
\hline Pesquisadora & 19 & Não acham que é direito de vocês usarem a quadra também? \\
\hline VM & 20 & Achar nós acha, mas nós não fala nada. \\
\hline Pesquisadora & 21 & Vocês não falam nada por quê? \\
\hline \multirow[t]{2}{*}{ VM } & 22 & Porque vai continuar a mesma coisa. Não vai mudar nada, professora. \\
\hline & 23 & Não vai mudar muita coisa. \\
\hline Pesquisadora & 24 & De onde vem a certeza de que nada vai mudar se vocês continuarem caladas? \\
\hline \multirow[t]{3}{*}{ VM } & 25 & Porque eles não vai tá lá todo tempo pra falar que as meninas podem fazer as \\
\hline & 26 & mesmas coisas que os meninos, então os meninos vai continuar fazendo as \\
\hline & 27 & mesmas coisas. \\
\hline \multirow[t]{2}{*}{ Pesquisadora } & 28 & Vocês acham que o professor não teria essa autonomia de fazer essa mudança \\
\hline & 29 & acontecer? \\
\hline VM & 30 & É... o professor tem, só que eles iam continuar falando que a quadra é só deles. \\
\hline Pesquisadora & 31 & O que vocês sentem? \\
\hline VM & 32 & Medo. \\
\hline
\end{tabular}

Não apenas os espaços sociais e ideológicos são ocupados pelo poder da dominação. O diálogo de VM mostra que, quando os espaços físicos também são ocupados, a reação feminina é a da própria anulação. O reconhecimento de que, mesmo que o professor ou a professora de educação física fizesse alguma coisa, que “eles iam continuar falando que a quadra é só deles” (linha 30), revela 
que o conformismo sustenta tanto um apagamento de voz, quanto uma transferência de ações para a responsabilidade do outro.

Knapp e Hall (1999, p. 29) dizem:

[...] como as palavras, os signos não-verbais têm múltiplos usos e significados; como as palavras, muitos signos não-verbais têm significados denotativos e conotativos. Somente pelo exame do contexto da interação somos capazes de avaliar com alto grau de confiança o modo como comportamentos específicos funcionam. Às vezes, os comportamentos parecem servir a uma única função, mas a compreensão das multifuncionalidades de um comportamento e da importância do contexto na determinação da função constitui pré-requisito necessário à discussão das funções do comportamento não-verbal.

Como significativas, as ações contribuem para a construção identitária dessas adolescentes assim como a delegação delas a outrem. Reforça essa ideia, de adesão a uma forma de silenciamento que lhes é imposto, também a ação de se esquivar a reclamar com a direção. O abuso de poder, pelo domínio, pelo controle, pela dissimulação ideológica (cf. THOMPSON, 2002), que se apoia na negativa ao direito de ter voz, se efetiva na variedade de formas de ações para ocupar o espaço físico, desde a efetiva tomada de iniciativa até o conformismo com o "não vai mudar muita coisa" (linha 23). A "voz" se torna, assim, um conjunto mais amplo de possibilidades de se significar no mundo, incluindo mudanças de comportamentos com respeito a ações concretas. Spivak (2010) já sinaliza isso quando diz que "a mulher como subalterna, não pode falar e quando tenta fazê-lo não encontra os meios para se fazer ouvir.”. Spivak (2010, pp. 87 e 88) prossegue:

Em um campo tão carregado, não é fácil fazer a pergunta sobre a consciência da mulher subalterna. É, portanto, ainda mais necessário lembrar os radicais pragmáticos de que essa questão não é uma digressão idealista. Embora nem todos os projetos feministas ou antissexistas possam ser reduzidos a esse, ignorá-lo é um gesto político não reconhecido que tem uma longa história e contribui com um radicalismo masculino que torna o lugar do investigador transparente. Ao buscar aprender a falar ao (em vez de ouvir ou falar em nome do) sujeito historicamente emudecido da mulher subalterna, o intelectual pós-colonial sistematicamente "desaprende" o privilégio feminino.

A subalternidade fica evidente na resposta da adolescente VM, que, ao ser perguntada sobre o que ela e as colegas de sala fazem na aula de educação física enquanto os meninos usam a quadra, responde: "Fica sentada." (linha 12). Nem só a voz é calada, ações e comportamentos também acompanham silenciamentos de voz. Embora haja por parte dela certa indignação ao falar, a obediência ao silenciamento é maior, e é como se, realmente, fosse inútil falar ou tentar lutar contra um sistema cristalizado e instaurado pelos meninos na escola. $\mathrm{O}$ abuso de poder por parte dos meninos fica tão ressaltado nesse diálogo que deixa transparecer que o que ocorre é mais sério e profundo do 
que aparenta. Não são apenas mulheres adolescentes acuadas por um determinado grupo de homens adolescentes de uma escola da periferia de Brasília. São futuras mulheres recebendo um recado claro do modo como se estrutura a sociedade nessa visão hegemônica: ser mulher em nossa sociedade é ser submissa, subestimada; é silenciar, é não ter para quem reclamar ou falar, é abdicar de ser ouvida. É emblemática a resposta de VM à pergunta: "Vocês não falam nada por quê? (linha 21)". Resposta: "Porque vai continuar a mesma coisa. Não vai mudar nada, professora. Não vai mudar muita coisa." (linhas 22 e 23).

Em síntese, o estudo dos dados indica a construção de identidades dominadoras pelas práticas discursivas de estudantes homens. O excerto 1, do colaborador MS, de 16 anos, relata sobre como ele se relacionava com sua namorada e de como ele exigia que ela se vestisse. Deixa clara, assim, a relação de dominação e poder que ele exercia sobre ela, e como ela reagia. $\mathrm{O}$ excerto 2 , da colaboradora MC, de 15 anos, aborda modos como, em nossa sociedade, ao homem é ensinado que ele não precisa reprimir os seus impulsos ou desejos, mesmo que para isso ele desrespeite a vontade alheia e, principalmente, a vontade de uma mulher. Na sequência do relato, fica claro o quanto ainda é presente e forte a dominação masculina legitimada pela sociedade. Os excertos 3 e 6 , da colaboradora YG, de 15 anos, e o excerto 4 da colaboradora BS, de 14 anos, levam ao questionamento da anulação da identidade feminina que, por vezes, também é imposta pela vestimenta. As mulheres são realmente o que vestem ou o que podem vestir? O excerto 5 , da colaboradora MF, de 15 anos, e o excerto 7 da colaboradora VM, de 14 anos, permitem vislumbrar o quanto a identidade feminina das adolescentes ainda passa pelo aval masculino dos adolescentes e sugere como elas se subjugam a eles e se violentam por qualquer afeto mínimo, nem que seja o da atenção.

Nos fragmentos de entrevistas com adolescentes aqui apresentados, observa-se, o que diz Zanello (2018, p. 270): "Um último ponto a se destacar no processo de subjetivação das mulheres é a performance do silêncio como fator mediador dos conflitos. Elas se calam, para manter o bem-estar dos outros. "

\section{CONSIDERAÇÕES FINAIS}

As entrevistas que constituem o objeto destas reflexões integram, como já mencionado, um corpus de pesquisa mais amplo e abrangente, mas se mostram suficientes para revelar práticas sociais e discursivas e ressaltam a prevalência de formas de ver e estar no mundo nitidamente associadas a valores masculinos - em detrimento de modos de ver o mundo segundo valores femininos. A isso, como vimos, Spivak (2010) chama de relação de subalternidade. Não apenas "vozes" femininas são pouco - ou quase nada - ouvidas nas práticas escolares aqui focalizadas, como, mesmo em momentos 
sociais e discursivos em que seriam esperadas, elas são substituídas por "vozes" reprodutoras de valores hegemônicos, masculinos. O que, no início destas reflexões, foi chamado de "discurso de insinuações" contra as mulheres torna-se, como se vê, um discurso claro como prática de exercício de poder - ou de abuso de poder, segundo Van Dijk (2008) - em práticas discursivas levadas a cabo em ambientes escolares.

O assentimento a esses valores ainda torna distante a possibilidade de resistência: a voz do subalterno não lhe pode ser "concedida" a partir de fora, pois só pode ser constituída a partir de uma construção identitária que nas práticas discursivas e sociais possam fazer frente às estruturas de poder e opressão. Retomando Spivak (2010), apenas trabalhando “contra” a subalternidade, é que se podem criar espaços nos quais o subalterno seja capaz de se articular e também de ser ouvido. Desvelar alguns modos de atuação dos discursos de manutenção da subalternidade é um primeiro passo para combatê-los e superá-los.

Ao ouvir o colaborador e as colaboradoras desta pesquisa, tornou-se claro como este campo de análise tem ainda muito a oferecer para que se compreenda e se explique os modos como os discursos servem para exercer a dominação de identidades masculinas sobre identidades femininas. O tema em questão, ao investigar dentro dos muros da escola, práticas que se estendem para além desse espaço físico e ideológico, tem sua relevância confirmada. Mais que isso, sugere a necessidade de aprofundamento de estudos que permitam uma intervenção nos modos de operar a ideologia nas nossas práticas socais. Tratando-se de práticas de docentes nas escolas, a violência simbólica, que caracteriza a dominação de um grupo sobre o outro, construída no discurso hegemônico, ressalta não apenas como objeto de pesquisa, mas, sobretudo, como problema social. Como tal, merece uma análise discursiva e social.

\section{REFERÊNCIAS BIBLIOGRÁFICAS}

ANGROSINO, M. Etnografia e observação participante. Porto Alegre: Artmed, 2009. Tradução de José Fonseca.

AUSTIN, J. How to do things with words. Oxford: Claredon Press, 1962.

BAUMAN, Z. Identidade. Rio de Janeiro: Jorge Zahar, 2005.

BOURDIEU, P. A dominação masculina. Tradução Maria Helena Kühner. 2. ed. Rio de Janeiro: Bertrand Brasil, 2002.

BOURDIEU, P. O poder simbólico. Tradução Fernando Tomaz. Lisboa: Difel, 1989.

FAIRCLOUGH, N. Discurso e mudança Social. Tradução de M. I. Magalhães. Brasília: UnB, 2001. 
FAIRCLOUGH, I.; FAIRCLOUGH, N. Political discourse analysis. A Method for Advanced Students. London: Routledge, 2012.

FLICK, U. Introdução à pesquisa qualitativa. 3. ed. Porto Alegre: Artmed, 2009.

HALL, S. A identidade cultura na pós-modernidade. 10. ed. Rio de Janeiro: DP\&A, 2005.

KNAPP, M. L.; HALL, J. A. Comunicação não-verbal: perspectivas básicas. In: KNAPP, M. L.; HALL, J. A. Comunicação não-verbal na interação humana. São Paulo: JSN, 1999.

LEVINSON, S. Pragmática. São Paulo: Martins Fontes, 2007 [1983]. Tradução de Luis Carlos Borges, Aníbal Mari; Revisão técnica de Rodolfo Ilari.

MEY, J. As vozes da sociedade. Campinas: Mercado de Letras, 2001.

PEDRO, E. R. Análise crítica do discurso: uma perspectiva sociopolitica e funcional. Lisboa: Caminho, 1998.

RAJAGOPALAN, K. Nova pragmática - fases e feições de um fazer. São Paulo: Parábola, 2010.

SOARES, M. Linguagem e escola - uma perspectiva social. São Paulo: Ática, 1986.

SPIVAK, G. C. Pode o subalterno falar? Belo Horizonte: UFMG, 2010.

THOMPSON, J. B. Ideologia e cultura moderna: teoria social crítica na era dos meios de comunicação de massa. Petrópolis: Vozes, 2002.

VAN DIJK, T. A. Discurso e poder. São Paulo: Contexto, 2008.

ZANELLO, V. Saúde mental, gêneros e dispositivos: cultura e processos de subjetivação. Curitiba: Appris, 2018. 